\title{
Bacteriological Profile and Antimicrobial Susceptibility Patterns of symptomatic bloodstream infection in Dhaka City
}

\author{
Mohammad Zakerin Abedin ${ }^{1 *}$, Md. Sifat Uz Zaman², Fayez Ahmed ${ }^{3}$, Farida Yeasmin ${ }^{4}$, Md. Babul \\ Aktar $^{1}$, Rasheda Yasmin Shilpi ${ }^{5}$ and Abdullah Akhtar Ahmed ${ }^{1}$
}

${ }^{1}$ Dept. of Microbiology, School of Biomedical Science, KhwajaYunus Ali University, Enayetpur, Sirajganj, Bangladesh;

${ }^{2}$ Dept. of Infection Prevention \& Control, Medlife Healthcare Limited, Dhaka, Bangladesh

${ }^{3}$ Dept. of Microbiology, Popular Diagnostic Centre, Dhaka, Bangladesh

${ }^{4}$ Faculty of Basic Medical and Pharmaceutical Science, University of Science and Technology

Chittagong, Chittagong, Bangladesh;

${ }^{5}$ Laboratory of Microbiology, Department of Botany, Jahangirnagar University, Savar, Bangladesh

\begin{abstract}
INTRODUCTION: Bacteremia, is regarded as a significant reason in all over the world Received: March 16, 2021 for morbidity and mortality in mainly sick patients. Invasion by microorganisms in blood constitutes Accepted: April 27, 2021 the critical issues in infectious disease. The aims and objectives are to find out the pathogenic agents infecting males and females in blood of different age groups and naturally used antimicrobial sensitivity profiles. METHODS: All the blood samples were collected aseptically and tested in Popular Diagnostic Centre, Dhaka, Bangladesh between May, 2020 and October, 2020. Total 305 blood specimens from both sexes of different age groups were collected. Cultural analysis was performed by Gram staining, phenotypic examination, biochemical and serological analysis. Finally, antibiotic susceptibility test was done against commonly used antibiotics. RESULTS: 96 (31.47\%) samples yielded a positive culture with predominant isolate being Salmonella typhi $(41.66 \%)$ though Salmonella spp., Salmonella typhi, Staphylococcus spp and Pseudomonas spp. were also detected. Like most of previous reports, Salmonella spp was predominant, this corroborates this study. But the profile of antimicrobial susceptibility of the detected organisms varied comparing studies which were done in the past. The isolates were found mostly resistant to nalidixic acid. Most of the pathogens showed tremendous susceptibility against ceftriaxone, cefixime, ceftazidime etc.

CONCLUSION: The antibiotic selection for the treatment of bacteraemia in patients should always be serious concern due to multidrug resistant (MRD) bacterial isolates. For proper treatment of antibacterial resistance and critical mortality and morbidity should be related with the sickness. For validating more reliability, this research requires further work.
\end{abstract}

Keywords: Bacterial isolates, bloodstream infection (BSI), Septicemia, antibiotic sensitive and resistance patterns

*Correspondence: Mohammad ZakerinAbedin, Assistant Professor \& Head, Dept. of Microbiology, School of Biomedical Science, KhwajaYunus Ali University, Enayetpur, Sirajganj, , Bangladesh, Mobile: +8801787923000 , Fax: +88075163867, Email: zakerin.du2016@gmail.com

\section{INTRODUCTION}

Blood is the connective tissue and indispensable for survival and proper functioning of human life. From limiting/clearing pathogens, providing nutrients, clotting wounds, dissemination of hormones, chemicals and toxin removals and antibiotics movement throughout our body, it plays a very important role in body survival and defence. Invasion by microorganisms in blood constitutes the critical issues in infectious disease. Microorganisms which are present in circulation of blood either transiently, continuously or intermittently, are a big threat to all organs inside our body [1]. The result of blood infection inside our body is genuine, quick results which may led to various organ disappointments, stun, passing (frequency of demise at 20\% to 50\%) and dispersed intravascular coagulation. Therefore, one of the significant facts of the laboratory is to identify and detect microbial pathogens on time [2].

For common bacterial isolates finding, blood culture techniques are used. The most common bacterial isolates are Staphylococcus aureus Salmonella paratyphi A, Salmonella typhi, Pseudomonas aeruginosa, E. coli, Klebsiella pneumoniae, Proteus spp, and $\beta$-hemolytic Streptococci [3].Blood culture vials and naked eye assessments once every 24 hour periods for the proof of development for 48 hours is considered as typical blood culture techniques and then the sub-culture on solid culture media the next day. Before the coverage, the negative vials cultures were further re-brooded for 5- days. Development has been occurred in the recent years in blood culture media, culture techniques in the frameworks which are completely machine driven [4]. By these frameworks, vials are screened 


\section{Biosight 2021; 02(01): 13-17}

every 8-10 minutes and a calculation of the final out is supported by evaluations of changes in relation to being developed. At present, the following frameworks are available: BD BACTEC $®$, Trek Diagnostic systems Inc., Inc., Becton Dickinson Microbiology systems, Durham, N.C. BacT/Alert®), Westlake, Ohio (ESP Sparks, OrganonTeknika ${ }^{\circledR}$ ), and bioMerieux, Inc. Hazelwood, Mo. (Vital) [2]. The main differentiation is the growth detection which exists normally within the systems [4]. In the systems, to incubate sample vials, the incubation period is normally programmed for 5-7 days. Bacterial antimicrobial susceptibility profile of normally varies among population because of difference in geography, local practices of antimicrobial prescribing and resistant bacterial strain's prevalence to a given area [5].

This research was done to find out the bacterial profile in blood culture and anti-biogram resistance profile of the isolated pathogens. It was done to find out the profile of isolated pathogens and designs out of the clinical specimens collected from patients in a renowned diagnostic center in capital city, Dhaka. Guiding the clinicians to initiate pragmatic antimicrobial therapy and to formulate a proper policy on antibiotic was the main objective of the research.

\section{METHODOLOGY:}

\section{STUDY AREA AND POPULATION:}

The data was collected from the Microbiology Lab of Popular Diagnostic Center which included outdoor-patients with acute febrile illness between July 2020 and September 2020. Blood samples $(n=305)$ were collected from suspected patients aseptically with bloodstream infection among entire aged group. About 3 ml of venous blood for children and $10 \mathrm{ml}$ for adults was collected aseptically using $70 \%$ alcohol and $2 \%$ tincture of iodine and then transferred into a BD BACTEC ${ }^{\mathrm{TM}}$ culture bottle according to the manufacturer guideline.

\section{BLOOD SAMPLING AND LABORATORY INVESTIGATIONS:}

The protocol was approved by the Ethical Review Committee of Popular Diagnostic Centre, Dhaka, Bangladesh. All the samples were taken aseptically for culture in an automated system. In this research, only aerobic cultures of blood were used. A 1-5 ml amount blood samples were inoculated properly into BD BACTEC ${ }^{\text {TM }}$ FX40 Peds Plus/F for 0-12 year-old children and 8-10 ml amount of blood samples were inoculated properly into BD BACTEC ${ }^{\mathrm{TM}}$ FX40 Aerobic/F for adults more than 12 years old. The clinical samples were then incubated quickly at $35 \pm 2^{\circ} \mathrm{C}$ in the BD BACTEC ${ }^{\mathrm{TM}}$ FX40 Instrument for a maximum of 3 days unless the result flagged positive. The vials which gave a positive result were then sub-cultured on Blood agar and MacConkey agar followed by CLSI routine microbiological techniques [6].

\section{BIOCHEMICAL \& SEROLOGICAL ANALYSIS AND GRAM STAINING:}

Simon citrate agar tubes, MIU, Klignar Iron Agar (KIA) and Oxidase tests were done for biochemical analysis to identify pathogens. Specific antisera (Becton, Dickinson and Company, Spark, USA) was used for confirmation of Salmonella spp. For distinguishing between Gram positive and negative bacteria, Gram staining methods were done [7].

\section{ANTIBIOTIC SENSITIVITY TEST:}

Kirby Bauer method of disc diffusion on Mueller Hinton agar was used for susceptibility testing of in-vitro antimicrobial for all the bacterial isolates. The antibiotics used in the test were Amoxycillin $(10 \mu \mathrm{g})$, Ceftriaxone $(30 \mu \mathrm{g})$, Cefixime $(5 \mu \mathrm{g})$, Ceftazidine $(10 \mu \mathrm{g})$, Cefuroxime $(30 \mu \mathrm{g})$, Ciprofloxacin $(5 \mu \mathrm{g})$, Azithromycin (10 $\mu \mathrm{g})$, Nalidix acid, Chloramphenicol $(30 \mu \mathrm{g})$, Gentamicin $(10 \mu \mathrm{g})$, Imepenem $(10 \mu \mathrm{g})$. In this research, we used Staphylococcus aureus (ATCC 25923) and Salmonella typhi (ATCC 14028) as control for the culture and sensitivity analysis.

\section{STATISTICAL ANALYSIS OF EXPERIMENTAL DATA:}

Excel 2016 and SPSS version 20 were used for analyzing the data. Descriptive statistics and chi-square tests were done for checking the statistical evaluation. $<0.5$ was the significant value of the $p$-value considered in this research.

\section{RESULT AND DISCUSSION:}

Blood infection has become very challenging; it is sometimes life threatening; that's why timely detection, identification, and antimicrobial sensitivity testing of blood-borne pathogens are very important in diagnostic microbiology laboratory. The physicians prescribe antimicrobial more than the actual need in developing countries like Bangladesh. All kinds of antibiotics are easily available in any medicine shop and anybody can buy it without doctor's prescription which are mainly responsible for developing resistant bacteria as well as blood culture negative results [8]. 


\title{
Biosight 2021; 02(01): 13-17
}

In the research, total of 305 blood specimens were analyzed by BD BACTEC ${ }^{\mathrm{TM}}$ FX40 from the outdoor patients of the diagnostic center. Among them, 96 (31.47\%) were positive. Out of 96 positive isolates, Gram-negative organisms were $87(90.63 \%)$ and Gram-positive organisms were $9(9.37 \%)$. Similar types of results were detected in Abedin MZ et al. 2020 [9]. In this research, the most predominant organisms were Salmonella typhi 40(41.66\%), followed by Salmonella spp.26 (27.10\%), Salmonella paratyphi A 13(13.54\%), Staphylococcus spp 9(9.37\%) and Pseudomonas spp. 8(8.33\%) which were presented in Fig-1.

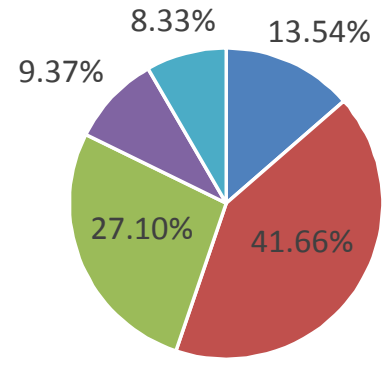

\author{
- Salmonella \\ Paratyphi A \\ - Salmonella typh \\ - Salmonella spp.
}

Fig-1: Frequency of bacterial isolates in suspected samples

The positive samples belonged maximum to adults comparing to children which is also found in the study of Iqbal $\mathrm{H}$ et al, 2020 [8].

\begin{tabular}{|l|c|c|c|c|}
\hline Isolated Pathogens & $\mathbf{0 - 1 2}$ years & $\mathbf{1 2 - 2 4}$ years & >24 years & Total \\
\hline Salmonella paratyphi A & 4 & 3 & 6 & 13 \\
\hline Salmonella typhi & 18 & 8 & 14 & 40 \\
\hline Salmonella spp. & 4 & 5 & 17 & 26 \\
\hline Staphylococcus spp. & 2 & 4 & 3 & 9 \\
\hline Pseudomonas spp. & 0 & 4 & 4 & 8 \\
\hline
\end{tabular}

Table 1: Frequency of bacterial isolates according to age groups [10].

In this research, Nalidixic Acid showed $100 \%$ resistance to Salmonella typhi as well as Salmonella paratyphiA which is a very serious issue. Ceftriaxone and Ceftazidime showed $100 \%$ sensitivity to Salmonella paratyphi A bacteria and Ceftriaxone, Cefixime, Ceftazidime, Ciprofloxacin showed 100\% sensitivity to Salmonella typhi. Antibiotic susceptibility test illustrated that the most sensitive antibiotics against Salmonella spp. were Ceftriaxone, Ceftazidime, Ciprofloxacin, Cefixime and Cefurixime and Staphylococcus spp were Ciprofloxacin, Gentamicin, Imepenem, Amoxicillin with a susceptibility rate of 100\%. Relatively similar result for Staphylococcus spp. was found in Abedin MZ et al 2020 [5]. For Pseudomonas spp. Imepenem showed tremendous susceptibility but showed the least effect against Amoxicillin. The pattern of antibiotic resistance of all organisms was predicated in the Table 2 and Table 3.

\begin{tabular}{|l|l|l|l|l|l|l|l|l|l|}
\hline \multirow{2}{*}{ Antibacterial agents } & \multicolumn{3}{|l|}{ Salmonella paratyphi A } & \multicolumn{3}{l|}{ Salmonella typhi } & \multicolumn{2}{l|}{ Salmonella spp. } \\
\cline { 2 - 11 } & $\mathrm{S}$ & $\mathrm{R}$ & $\mathrm{M}$ & $\mathrm{S}$ & $\mathrm{R}$ & $\mathrm{M}$ & $\mathrm{S}$ & $\mathrm{R}$ & $\mathrm{M}$ \\
\hline Amoxycillin $(10 \mu \mathrm{g})$ & 92.3 & 7.7 & 0 & 75 & 25 & 0 & 42.3 & 50.0 & 7.7 \\
\hline Ceftriaxone $(30 \mu \mathrm{g})$ & 100 & 0 & 0 & 100 & 0 & 0 & 96.2 & 0 & 3.8 \\
\hline Cefixime $(5 \mu \mathrm{g})$ & 93.2 & 7.7 & 0 & 100 & 0 & 0 & 96.2 & 3.8 & 0 \\
\hline Ceftazidime $(10 \mu \mathrm{g})$ & 100 & 0 & 0 & 100 & 0 & 0 & 100 & 0 & 0 \\
\hline Cefuroxime $(30 \mu \mathrm{g})$ & 100 & 0 & 0 & 97.5 & 0 & 2.5 & 100 & 0 & 0 \\
\hline Ciprofloxacin $(5 \mu \mathrm{g})$ & 92.3 & 7.7 & 0 & 100 & 0 & 0 & 96.2 & 0 & 3.8 \\
\hline Azithromycin $(10 \mu \mathrm{g})$ & 69.2 & 23.1 & 7.7 & 72.5 & 15 & 12.5 & 46.2 & 23.1 & 30.7 \\
\hline Nalidixic acid & 0 & 100 & 0 & 0 & 100 & 0 & 0 & 100 & 0 \\
\hline Chloramphenicol $(30 \mu \mathrm{g})$ & 0 & 100 & 0 & 92.5 & 0 & 7.5 & 84.6 & 15.4 & 0 \\
\hline
\end{tabular}

Table 2: Antibiotic susceptibility Profile of Salmonella spp isolated from samples of blood (\%)

Note: $\mathrm{S}=$ Sensitive, $\mathrm{R}=$ Resistance, $\mathrm{M}=$ Medium sensitive

\begin{tabular}{|l|l|l|}
\hline Antibacterial agents & Staphylococcus spp. & Pseudomonas spp.
\end{tabular}


Biosight 2021; 02(01): 13-17

\begin{tabular}{|l|l|l|l|l|l|l|}
\hline & S & R & M & S & R & M \\
\hline Amoxycillin $(10 \mu \mathrm{g})$ & 100 & 0 & 0 & 0 & 100 & 0 \\
\hline Gentamicin $(10 \mu \mathrm{g})$ & 100 & 0 & 0 & 75 & 25 & 0 \\
\hline Imepenem $(10 \mu \mathrm{g})$ & 100 & 0 & 0 & 100 & 0 & 0 \\
\hline Ciprofloxacin $(5 \mu \mathrm{g})$ & 100 & 0 & 0 & 87 & 13 & 0 \\
\hline
\end{tabular}

Table 3: Antibiotic susceptibility Profile of others isolated from samples of blood (\%).

Note: $\mathrm{S}=$ Sensitive, $\mathrm{R}=$ Resistance, $\mathrm{M}=$ Medium sensitive

\section{CONCLUSION:}

In the conclusion, we have performed blood culture by automated BD BACTECTM ${ }^{\mathrm{TM}}-40$ and in vitro analysis of antibiogram patterns from the patients who were suffering from acute febrile illness sought treatment at tertiary level hospital in Bangladesh. The blood culture analysis revealed $31.47 \%$ positive bacteremia patients with numbering of suspected isolates were Staphylococcus aureus, Salmonella typhi, Salmonella paratyphi A, Salmonella spp and Pseudomonas spp. The fourth generation antibiotic Ceftriaxone, Cefixime, Ceftazidime etc showed higher susceptibility to almost all organisms, but Nalidixic acid showed least sensitivity. Very careful consideration needs to be taken before selecting the appropriate antibiotic for the treatment. Serious concern is imposed by presence of antibiotic resistant organism regarding antibiotic choosing for the treatment of patient with bacteremia.

\section{AUTHORS CONTRIBUTIONS}

Abedin MZ and Ahmed AA designed the experiments, Ahmed F collected the samples and analyzed, Yeasmin F carried out the study, Abedin MZ and Shilpi RY participated in design to draft, and Zaman MSU wrote the manuscript. Abedin MZ and Shilpi RY supervised and reviewed the manuscript; all the authors read and approved the final manuscript.

\section{ETHICS APPROVAL AND CONSENT TO PARTICIPATE}

Not applicable.

HUMAN AND ANIMAL RIGHTS

Not applicable.

\section{CONSENT FOR PUBLICATION}

Not applicable.

\section{AVAILABILITY OF DATA AND MATERIALS}

None.

\section{FUNDING}

None.

\section{CONFLICT OF INTEREST}

The authors declare no conflict of interest, financial or otherwise.

\section{ACKNOWLEDGEMENTS}

We thank to all laboratory personnel of microbiology laboratory at Khwaja Yunus Ali University. We gratefully acknowledge the managing director of the Popular Diagnostic centre Ltd, Dhaka to allow us to conduct this study. A big special thanks to the managing director of Popular Diagnostic centre Ltd, Dhaka for cooperation of this research.

\section{REFERENCES:}

1. Vasudeva N, Nirwan PS, Shrivastava P. Bloodstream infections and antimicrobial sensitivity patterns in a tertiary care hospital of India. TherAdv Infect Dis 2016; 3: 119-27.

2. Forbes BA, Sahm DF, Weissfeld AS. Bailey and Scott's Diagnostic Microbiology. 11th ed. St. Luise Mosby 2002.

3. Assad Am, Quresh MA, Hasan SM. Clinical significance of coagulase negative Staphylococcus clinical isolates from nosocomial bloodstream infections. Journal Infectious Diseases 2015: 48(5), 356-360.

4. Reisner BS, Woods GL. Times to detection of bacteria and yeast in 9240 Blood culture bottles. J ClinMicrobiol 1999; 37: 2024-6. 


\section{Biosight 2021; 02(01): 13-17}

5. Abedin MZ, Yeasmin F, Faruque MO et al. Enumeration of the antimicrobial susceptibility patterns of different bacterial isolates from ENT patients with ear infections. Eur. J. Med. Health Sci.2020: 2(4), 68-73. https://doi.org/10.34104/ejmhs.020.068073

6. Clinical and Laboratory Standards Institute (CLSI). Performance standards for antimicrobial susceptibility testing. Twenty-second informational supplement. Wayne, PA, USA. CLSI 2015.

7. Abedin, M.Z.,Aktar MB , Zaman MSUet al. Occurrence and Antimicrobial Susceptibility Profiling of Bacteria Isolated from Cultured Pangas Catfish (Pangasiuspangasius) and Climbing Perch (Anabas testudineus) Fishes. J Marine BiolAquacult. 2020: 6(1): 7-12. https://doi.org/10.15436/2381-0750.20.2743

8. Iqbal H, Mahboob N, Ahmed M, Mamun KZ, Rahim A, Azad KA. Bacteriological profile and antimicrobial susceptibility patterns of blood culture isolates among febrile patients in a Tertiary care hospital, Bangladesh. Journal of Dhaka Medical College. 2018; 27(2):114-22.

9. Abedin MZ,Jarin L, Rahman MR, Islam R. (2020).Culture positivism exploitation through automated fluorescentsensor technology from patients with blood stream 10infections. J AdvBiotechnolExpTher. 2020; 3(3): 165-170. https://doi.org/10.5455/jabet.2020.d122

10. Abedin MZ, Faruque MO, Sifat Uz Zaman M, Nasim R, Hasan R, Jarin L, Islam R, Uddin ME (2020). Prevalence and In Vitro Antibiogram Patterns of Urinary Tract Pathogens in Rural Hospitals in Bangladesh. JCBPS; Section B; May 2020-July 2020, Vol. 10, No. 3; 401-409. doi: 10.24214/jcbps.b.10.3.40109. 